\title{
Bond strength of self-etching adhesives to dentin surface after smear layer removal with ultrasonic brushing
}

\author{
Nattawit NIYOMSUJARIT, Pisol SENAWONGSE and Choltacha HARNIRATTISAI \\ Department of Operative Dentistry and Endodontics, Mahidol University, 6 Yothee Road, Rajthewee, Bangkok 10400, Thailand \\ Corresponding author, Nattawit NIYOMSUJARIT; E-mail: nattawit.niy@mahidol.ac.th
}

\begin{abstract}
This study determined the micro-shear bond strength ( $\mu \mathrm{SBS})$ of two self-etching adhesives to dentin surface after smear layer removal with a novel ultrasonic brushing method. Ninety-five dentin discs were ground flat with diamond burs and divided into 5 groups; no treatment (control), brushing with a custom-made brush for 10 and $30 \mathrm{~s}$ without and with ultrasonic application. The smear layer thickness was evaluated using SEM. The $24 \mathrm{~h} \mu \mathrm{SBS}$ of Clearfil SE Bond (CSE) and Clearfil Tri S Bond (CTS) to these dentin surfaces were evaluated. Smear layer thickness decreased significantly from control, brushing without, and brushing with ultrasonic groups, respectively. The $\mu$ SBS of CSE were higher than CTS in all groups. The $\mu$ SBS were improved with ultrasonic brushing for $30 \mathrm{~s}$ for both adhesives. Ultrasonic brushing is the effective method in mechanical smear layer removal which can improve bond strength of self-etching adhesives to ground dentin.
\end{abstract}

Keywords: Ultrasonic brushing, Dentin bond strength, Self-etching adhesives, Smear layer, Resin-dentin interface

\section{INTRODUCTION}

Current trends of adhesive are focus on simplicity of bonding procedure leading to increasing popularity of self-etching adhesive. As part of restorative procedures, the smear layer which covers the dentin surface is a consequence of cavity preparation. Smear layer must be removed, modified or impregnated by the resin to allow for priming and bonding of adhesive between the tooth and the restorative material ${ }^{1,2}$.

Self-etching adhesive combine the etching and priming step which create the demineralization and resin penetration continuously that might avoid the problems of acid etchant and more user-friendly. Nevertheless, the weak acidity of self-etching adhesive can be compromised by buffering effect of smear layer especially in thick and dense smear layer resulting in decreasing of bond strength and durability ${ }^{3-6)}$. Therefore, the smear layer removal, thinning or loosing might be necessary to establish the effective dentin bonding of self- etching adhesive.

Recently, several studies confirmed that acidic monomers in self-etching adhesive could bond chemically to calcium in hydroxyapatite of dentin. Therefore, method of smear layer removal without decalcification of the dentin surface would be preferred to preserve hydroxyapatite at the interface which will provide calcium for chemical bonding to the functional monomer ${ }^{2}$. Ethylenediamine tetraacetic acid (EDTA) can be used as an acid etchant with minimal demineralization of the dentin surface. It also showed the advantage of effective smear layer removal and inhibitory effect on collagenbound matrix metalloproteinases $(\mathrm{MMPs})^{7-9)}$. However, the water can wash out EDTA and incomplete resin infiltration might be still occured also ${ }^{10)}$. Kusunoki et al. reported the smear layer removal mechanically with high water pressure spray ( $4 \mathrm{~atm}, 3 \mathrm{~min}$ ) to avoid the adverse effect of acid etchant but it can be achieved hardly in clinical situation ${ }^{11)}$.

The ultrasonic cleaning is another effective cleaning procedure in modern dentistry. Ultrasonic waves generate and evenly distribute cavitation implosions in a liquid medium which is effective surface contaminants cleaning ${ }^{12,13)}$. The ultrasonic is currently applied to scaling and subgingival cleaning in periodontology and root canal irrigation in endodontology ${ }^{14-17)}$. Therefore, it is interesting to apply the ultrasonic frequency combine with brushing technique to remove smear layer on prepared dentin surface prior self-etching adhesive application to improve the bond strength of self-etching adhesives to the dentin.

The purposes of this study were 1) to evaluate the thickness of dentin smear layer and 2) to compare the micro-shear bond strength ( $\mu \mathrm{SBS})$ of two different selfetching adhesives to dentin surface after brushing with and without ultrasonic application at different times. The null hypotheses were, after different ultrasonic brushing condition of the dentin surface, 1) There are no differences in smear layer thickness and 2) There is no difference in bond strength of these self-etching adhesives to dentin surface.

\section{MATERIALS AND METHODS}

This study was performed under ethical approval by Faculty of Dentistry and Faculty of Pharmaceutical Sciences Institutional Review Board, Mahidol University (project number; MU-DT/PY-IRB 2014/DT108). The materials used and application methods are in Table 1.

\section{Tooth specimen preparation}

Ninety-five extracted human premolars were used in this study. The occlusal dentin disc approximately $2 \mathrm{~mm}$ thick was prepared perpendicularly to the long axis of 
Table 1 Materials used in this study, their composition and application procedures

\begin{tabular}{|c|c|c|c|c|c|}
\hline Adhesive & Type & Composition & Lot No. & $\mathrm{pH}$ & $\begin{array}{l}\text { Manufacturer's } \\
\text { instruction }\end{array}$ \\
\hline \multirow{2}{*}{$\begin{array}{l}\text { Clearfil SE } \\
\text { Bond } \\
\text { (Kuraray } \\
\text { Medical, } \\
\text { Osaka, } \\
\text { Japan) }\end{array}$} & \multirow{2}{*}{$\begin{array}{l}2 \text { steps, } \\
\text { self-etching } \\
\text { adhesive }\end{array}$} & $\begin{array}{l}\text { Primer: } 10-\mathrm{MDP} \text {, HEMA, hydrophilic } \\
\text { dimethacrylate, di-camphorquinone, } \\
\text { N,N-diethanol-p-toluine, water }\end{array}$ & 01232A & & $\begin{array}{l}\text { 1. apply primer } 20 \mathrm{~s} \\
\text { 2. dry with mild air }\end{array}$ \\
\hline & & $\begin{array}{l}\text { Bonding: 10-MDP, Bis-GMA, HEMA, } \\
\text { hydrophobic dimethacrylate, } \\
\text { di-camphorquinone, N,N-diethanol-p-toluine, } \\
\text { silanated colloidal silica }\end{array}$ & 01860A & 2 & $\begin{array}{l}\text { 3. apply bonding } \\
\text { 4. air flow gently } \\
\text { 5. light cure } 10 \mathrm{~s}\end{array}$ \\
\hline $\begin{array}{l}\text { Clearfil } \\
\mathrm{S}^{3} \text { bond } \\
\text { (Kuraray } \\
\text { Medical) }\end{array}$ & $\begin{array}{l}\text { All-in-one } \\
\text { adhesive } \\
\text { (one-bottle) }\end{array}$ & $\begin{array}{l}\text { 10-MDP, Bis-GMA, HEMA, } \\
\text { hydrophobic dimethacrylate, } \\
\text { di-camphorquinone, ethanol, water, } \\
\text { silanated colloidal silica }\end{array}$ & 00178A & 2.7 & $\begin{array}{l}\text { 1. apply adhesive } 20 \mathrm{~s} \\
\text { 2. high- pressure air } \\
\text { flow } \\
\text { 3. light cure } 10 \mathrm{~s}\end{array}$ \\
\hline
\end{tabular}

10-MDP: 10methacryloyloxydecyl dihydrogen phosphate; HEMA: 2-hydroxyethyl methacrylate; Bis-GMA: 2,2-bis[4-(2hydroxy-3-methacrylyloxy-propoxy)-phenyl]propane

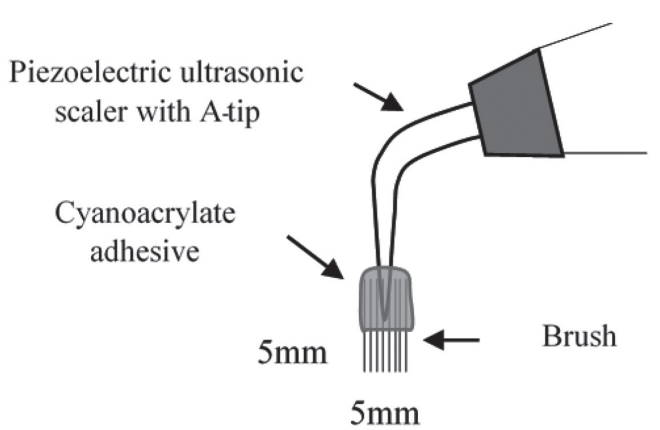

Fig. 1 Schematic picture of a custom-brush used in this study.

teeth at $2 \mathrm{~mm}$ coronally from cemento-enamel junction to exposed flat dentin surface.

\section{Custom-made brush fabrication}

A custom made brush was fabricated from a tuff which separated from a commercial brush (Colgate $360^{\circ}, 10$ $\mu \mathrm{m}$ bristle diameter, Colgate-Palmolive, NY, USA,). The bristles were attached to a tip of ultrasonic scaler with cyanoacrylate adhesive (Model Repair II Blue, Dentsply, SANKIN, Tokyo, Japan). The cyanoacrylate adhesive was adapted into shape which will not interfered water flow from the scaler. Brush length was $5 \mathrm{~mm}$ measured from tip to cyanoacrylate adhesive and brush diameter was $5 \mathrm{~mm}$. The bristle was made from nylon type 6.12 . Schematic picture of custom-brush was shown in Fig. 1. Individual brush was used for each experimental group and discarded. The axis of brush was places perpendicular to the dentin surface and gently moved forth and back 2 cycles per second without any pressure to avoid variation of brushing pressure. Pressure which applied on the tip of bristle was from the weight of the scaler tip.
Dentin preparation prior adhesive application

The dentin discs were prepared using 10 passes of high speed cylindrical shaped diamond burs with 125 $\mu \mathrm{m}$ abrasive particles (FG712C, Intensiv, Montagnola, Switzerland) then divided into 5 groups of different surface preparation.

Group 1 (no treatment group, Control); no any additional treatment.

Groups 2, 3 (brushing, B); the exposed dentin surface was brush using custom-made brush which attached and adapted to the tip of an ultrasonic scaler and operated with water flow without ultrasonic frequency (A-tip, P5 Newtron XS Satelec Acteon, Merignac, France), water flow rate; $40 \mathrm{~mL} / \mathrm{min}, 0 \mathrm{~Hz}$ ). Operating time was 10 and $30 \mathrm{~s}$ for groups 2 and 3, respectively.

Groups 4, 5 (ultrasonic brushing, UB); the exposed dentin surface was brush using custom-made brush which attached and adapted to the tip of an ultrasonic scaler (A-tip, P5 Newtron XS, water flow rate; $40 \mathrm{~mL} /$ $\min , 36 \mathrm{kHz}$ ). Operating time was 10 and $30 \mathrm{~s}$ for groups 4 and 5 , respectively.

Part I; Observation of dentin surface and smear layer thickness

Pre-cut of transversal grooves on non-evaluated sides of dentin disc with carborundum disc before surface preparation (3 specimens/group, 15 specimens totally). After surface preparation, specimens were fixed in $2.5 \%$ glutaraldehyde in $0.1 \mathrm{M}$ Sorensen phosphate buffer $(\mathrm{pH}$ 7) at $4^{\circ} \mathrm{C}$ for $12 \mathrm{~h}$, rinsed with $0.2 \mathrm{M}$ Sorensen phosphate buffer for $1 \mathrm{~h}$ in three different baths, and rinsed for 1 min with deionized water. The discs were dehydrated in ascending concentration of ethanol: immersion for 20 min in 25, 50 and $75 \%$ ethanol, 10 min in 95\% ethanol and $50 \mathrm{~min}$ in $100 \%$ ethanol. The discs were placed in hexamethyldisilazane (HMDS) for $10 \mathrm{~min}$ and allowed to air-dry for $10 \mathrm{~min}$. The discs were carefully fractured by a scalpel blade and a hammer.

Then, all dentin surfaces were observed under SEM 
(JSM 6610LV, JEOL, Tokyo, Japan) at magnification of $\times 3,000$ and $\times 7,000$. The smear layer thickness was determined at 5 neighboring sites of specimen and calculated for mean thickness in $\mu \mathrm{m}$.

Part II; Evaluation of the effect of ultrasonic brushing on $\mu$ SBS of self-etching adhesives

After dentin surface preparation, each group was divided into 2 subgroups depending on the adhesive used [Clearfil SE Bond (CSE) and Clearfil S3 Bond (CTS), 5 specimens/subgroup, 50 specimens totally]. Each adhesive was applied on the dentin surface following the manufacturer's instruction as shown in Table 1. Prior to the light curing step, a plastic tube $0.8 \mathrm{~mm}$ in diameter and $1.0 \mathrm{~mm}$ in height was placed on the uncured adhesive surfaces ( 2 positions/specimen, $4 \mathrm{~mm}$ apart from each other). The adhesive was photo-polymerized using a light curing unit (Bluephase G2, Ivoclar Vivadent, Schaan, Liechenstein) with the light intensity of $1,200 \mathrm{~mW} / \mathrm{cm}^{2}$ for $10 \mathrm{~s}$ to stabilized the plastic tube on dentin surface. After curing, a resin composite (Filtek Z350, A3, 3M ESPE, St. Paul, MN, USA) was placed into the plastic tube and cured for $40 \mathrm{~s}$. In this manner, a small cylinder of resin composite was bonded to the dentin surfaces. All specimens were stored in distilled water at $37^{\circ} \mathrm{C}$ for 24 $\mathrm{h}$ and the plastic tubes were carefully removed using a scalpel blade before testing.

Before testing, the specimens were checked under a light microscope. Specimens presented any defect at the bonding interfaces, such as interfacial gap formation or bubble inclusion, were excluded from this study. The restored specimens with proper resin cylinder were placed on a universal testing machine with a cyanoacrylate adhesive. A thin wire was looped around the resin cylinder and gentle hold flush against the resin-dentin interface. A shear force was applied at crosshead speed of $0.5 \mathrm{~mm} / \mathrm{min}$ to failure.

\section{Mode of failure classification}

The fracture surfaces of both resin and dentin were examined under SEM at magnification of $\times 100$ and $\times 500$ to determine the mode of failure. Failure modes were classified as

Adhesive failure: fracture area occurred involving at least $75 \%$ at the bonded interface between dentin or resin composite and adhesive.

Cohesive failure in dentin: fracture area occurred involving at least $75 \%$ at the bonded interface between dentin.

Cohesive failure in resin composite: fracture area occurred involving at least $75 \%$ at the bonded interface between resin composite.

Mixed failure: fracture area occurred involving in combination of adhesive failure and cohesive failure in resin composite or dentin, which is less than $75 \%$ each.

Part III; Observation of micromorphology of the resindentin interface

The specimens were prepared in the same manner as the specimens for the bond strength measurement
(3 specimens/ subgroup, 30 specimens totally). The specimens were sectioned vertically through the bonded interface by a low speed saw. All cut specimens were stored in buffer formalin for $24 \mathrm{~h}$ and rinsed for $1 \mathrm{~h}$. Each cut specimen was then embedded with the sectioned side facing to the outside of an epoxy resin. The sectioned surfaces were ground with 600-, 800-, 1000-, and 1200 grit silicon carbide papers, and then polished with diamond paste down to a $0.25 \mu \mathrm{m}$ particle size. Subsequently, the specimens were subjected to a $10 \%$ phosphoric acid treatment for $3 \mathrm{~s}$, followed by $5.25 \%$ sodium hypochlorite immersion for $3 \mathrm{~min}$. Then, all specimens were coated with gold and observed under SEM at magnification of $\times 10,000$.

\section{Statistical analysis}

The statistical analysis of the measured results was assessed using a statistics program (SPSS Statistics 20.0, IBM, Chicago, IL, USA). Two-way ANOVA was used to test differences in the mean thickness between experimental groups. Dunnett T3 multiple comparison was further used to find out which groups are significantly different from the other and $t$-test was further used to find out which experimental groups are significantly different from the control group. Threeway ANOVA was used to test differences in the mean bond strengths between experimental groups. Duncan multiple comparison was further used to find out which groups are significantly different from the others and $t$-test was further used to find out which experimental groups are significantly different from the control group for each adhesive.

All statistical analysis was analyzed with a confidential level of $95 \%$

\section{RESULTS}

Part I; Observation of dentin surface and smear layer thickness

The smear layer thickness decreased significantly from no treatment group to brushing groups and ultrasonic brushing groups, respectively. For the groups of brushing without ultrasonic application, $10 \mathrm{~s}$ of application time showed the thicker smear layer than $30 \mathrm{~s}$. The ultrasonic brushing groups had the thinnest smear layer with no significant difference in thickness was found between 10 and $30 \mathrm{~s}$ of application time. The statistical value of mean difference between control and experimental groups were demonstrated in Table 2.

Morphological characteristics of dentin surface after treatment of each group according to smear layer removal technique were presented in Fig. 2. Crosscut views of dentin and smear layer thickness were presented in Fig. 3. All prepared dentin surfaces showed typical bur-cut characteristic. For no treatment group, the thickest smear layer was detected and the openings of dentinal tubules underlying the prepared surface were not found Both B10s and B30s groups showed thinner smear layer than the no treatment group. Most dentinal tubules could not be detected similar to the no treatment 
Table 2 Smear layer thickness [means (S.D.); $\mu \mathrm{m}$ ] according to different ultrasonic application and brushing time

\begin{tabular}{ccccccc}
\hline \multirow{2}{*}{ Control } & \multicolumn{2}{c}{ Brushing without ultrasonic application } & & \multicolumn{3}{c}{ Brushing with ultrasonic application } \\
\cline { 2 - 3 } \cline { 5 - 7 } & Time $=10 \mathrm{~s}$ & Time=30 s & & Time=10 s & Time=30 s \\
\hline $5.17(0.69)^{\mathrm{a}}$ & $4.02(0.8)^{\mathrm{a}}$ & $2.30(0.42)^{\mathrm{b}}$ & & $0.19(0.04)^{\mathrm{c}}$ & $0.16(0.06)^{\mathrm{c}}$ \\
\hline
\end{tabular}

The different superscript letters indicate significant differences $(p<0.05)$.

(a)
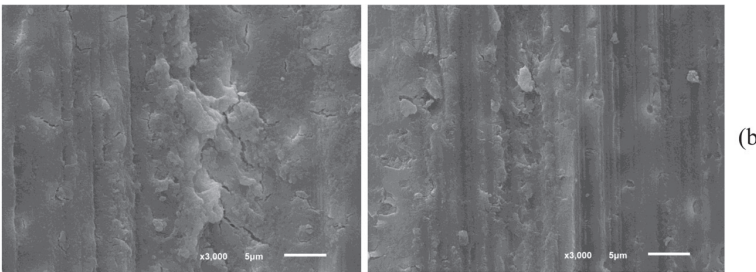

(c)

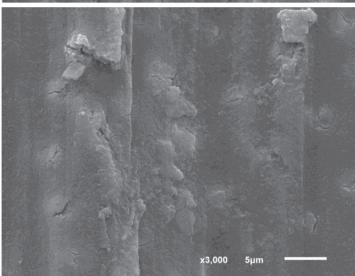

(e)

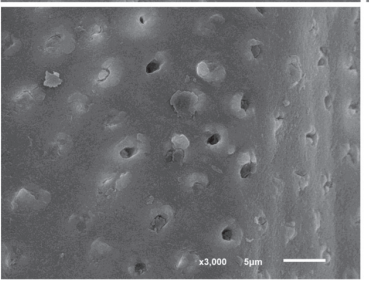

Fig. 2 SEM image of dentin surface at $\times 3,000$ after different treatment: (a) no treatment, (b) B10s, (c) B30s, (d) UB10s, (e) UB30s.

(b) (a)

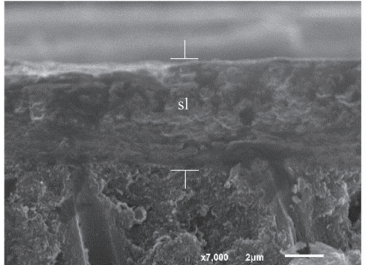

(c)
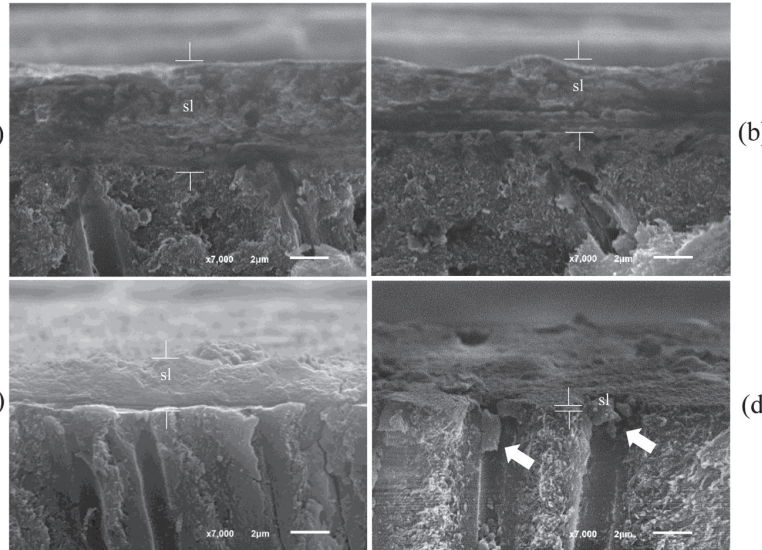

(e)
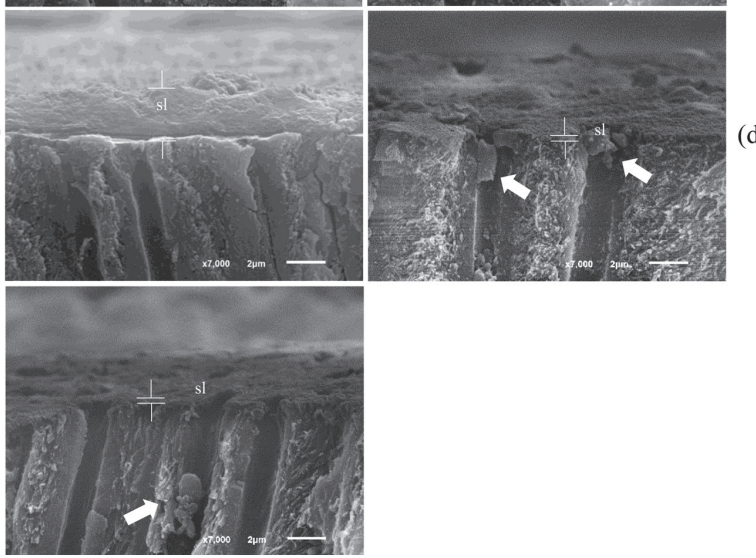

Fig. 3 SEM image of cross-cut dentin at $\times 7,000$ after different treatment: (a) no treatment, (b) B10s, (c) B30s, (d) UB10s, (e) UB30s.

sl; smear layer, white arrow; smear plug

Table 3 Micro-shear bond strength value [means (S.D.); MPa]; according to different ultrasonic application, brushing time and type of adhesive

\begin{tabular}{|c|c|c|c|c|c|c|}
\hline \multicolumn{2}{|c|}{ Group description } & \multirow{2}{*}{ Control } & \multicolumn{2}{|c|}{$\begin{array}{l}\text { Brushing without } \\
\text { ultrasonic application }\end{array}$} & \multicolumn{2}{|c|}{$\begin{array}{l}\text { Brushing with } \\
\text { ultrasonic application }\end{array}$} \\
\hline & & & Time $=10 \mathrm{~s}$ & Time $=30 \mathrm{~s}$ & Time $=10 \mathrm{~s}$ & Time $=30 \mathrm{~s}$ \\
\hline \multirow{2}{*}{$\begin{array}{l}\text { Type of } \\
\text { adhesive }\end{array}$} & CSE & $32.95(3.67)^{\mathrm{b}}$ & $29.99(5.53)^{\mathrm{b}}$ & $31.53(6.51)^{\mathrm{b}}$ & $31.79(4.95)^{\mathrm{b}}$ & $40.62(2.88)^{\mathrm{a}}$ \\
\hline & CTS & $21.41(3.29)^{\mathrm{c}}$ & $20.77(4.52)^{\mathrm{c}}$ & $21.21(4.89)^{\mathrm{c}}$ & $22.52(5.42)^{\mathrm{c}}$ & $30.08(2.84)^{\mathrm{b}}$ \\
\hline
\end{tabular}

The different superscript letters indicate significant differences $(p<0.05)$.

group. Dentinal tubule can be traced with presence of smear plug in UB10s group. Some dentinal tubules were opened in UB30s group.

Part II; Evaluation of the effect of ultrasonic brushing on $\mu$ SBS of self-etching adhesives

Only $\mu$ SBS from ultrasonic brushing for 30 s group was significantly higher than control group and was the highest when compare to the others for both adhesives.
CSE demonstrated higher $\mu$ SBS than CTS irrespective of surface treatment. The statistical value of mean difference between control and experimental groups were demonstrated in Table 3.

\section{Failure mode distribution}

Most of failure mode were adhesive failure. Mixed failure increased in group of brushing or ultrasonic brushing and also in group of increasing operating time. Cohesive 


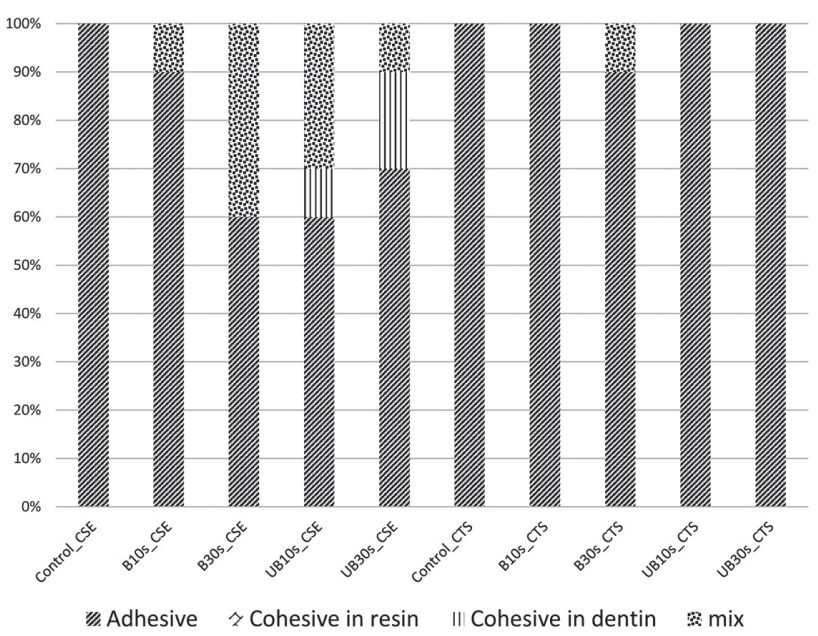

Fig. 4 Comparison of the percentages of failure mode distribution of fracture specimens of 2 self-etching adhesives to different dentin surface treatment. Cohesive failure in resin composite was not found in any specimen.

(a)
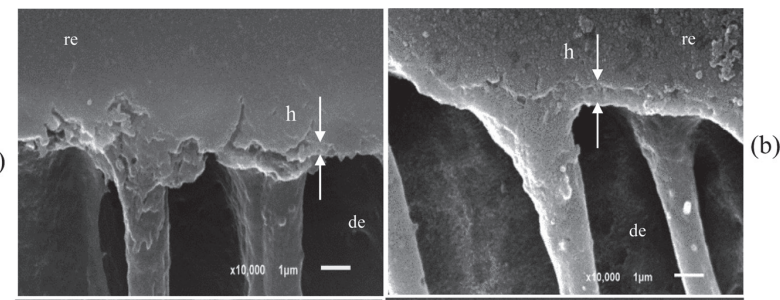

(c)
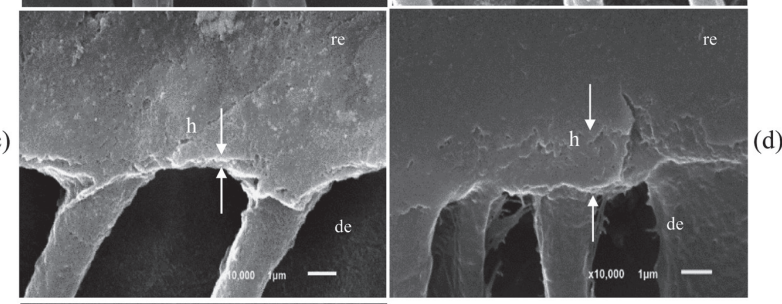

(e)

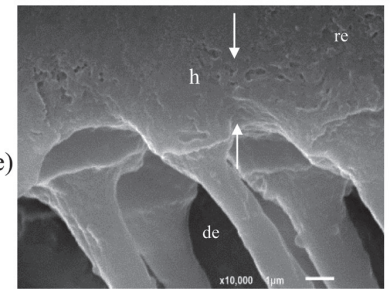

Fig. 5 SEM image of resin-dentin interface of CSE to different dentin treatment at $\times 10,000$ : (a) no treatment, (b) B10s, (c) B30s, (d) UB10s, (e) UB30s.

re; resin, de; dentin, h; hybrid layer

failure in dentin were found in groups of 10 and $30 \mathrm{~s}$ ultrasonic brushing. The cohesive failure in resin composite was not found in any specimen. Distribution of failure mode of both adhesives to different dentin surface treatment was demonstrated in Fig. 4.

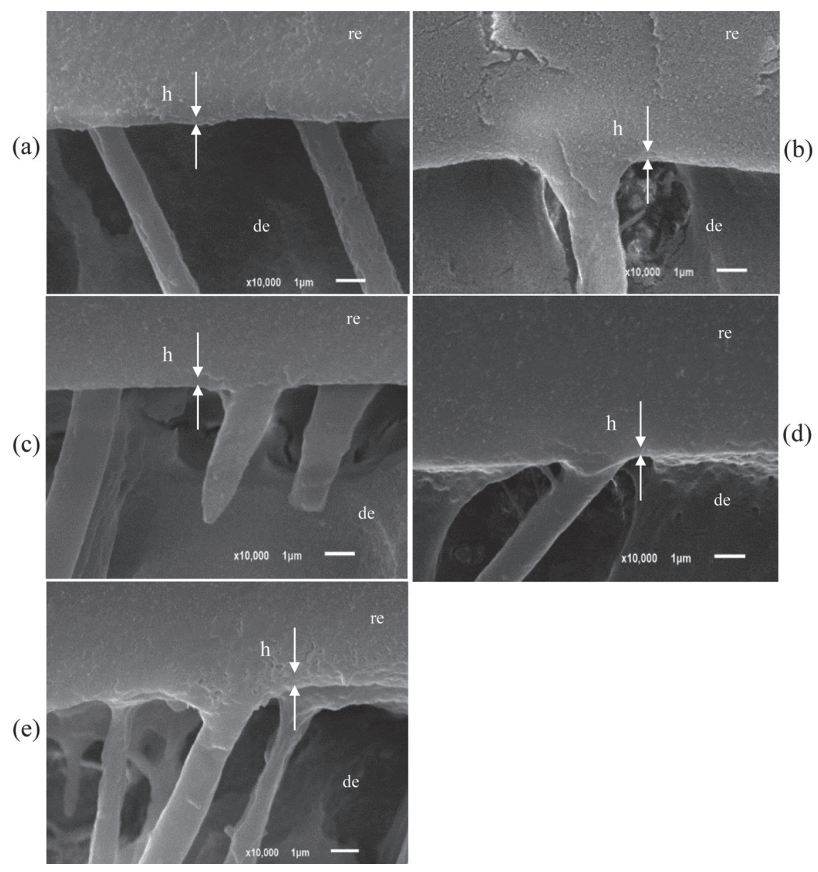

Fig. 6 SEM image of resin-dentin interface of CTS to different dentin treatment at $\times 10,000$ : (a) no treatment, (b) B10s, (c) B30s, (d) UB10s, (e) UB30s.

re; resin, de; dentin, h; hybrid layer

Part III; Observation of micromorphology of the resindentin interface

The SEM micrographs at $\times 10,000$ magnification of resin-dentin interface of CSE groups were demonstrated in Fig. 5 and CTS groups in Fig. 6. The hybrid layer thickness was approximately $1-2 \mu \mathrm{m}$ in CSE group. CTS group showed extremely thin hybrid layer which was difficult to be measured under the SEM. The difference of resin tags and hybrid layer between both adhesives were found. For same preparation, the resin tags of CSE were conical-shaped and thicker than those of the CTS which were cylindrical-shaped. The hybrid layer of CSE and dentin after treated with UB30s revealed the thickest hybrid layer (about $2 \mu \mathrm{m}$ ), more number of resin tags and boarder base of resin tags than other groups as well.

\section{DISCUSSION}

As a routine procedure for restoration, dentin preparation always be achieved with diamond bur and the smear layer will be created as a consequence. The smear layer act as the obstacle which neutralized the acidity of primer and reduce the penetration of resin adhesive $e^{18,19}$. Many studies reported the adverse effects of smear layer on dentin bond strength of self-etching adhesive ${ }^{3-6)}$. The bur-cut smear layer which is more compact resulting in lower bond strength of self-etching adhesive than that of same thickness SiC paper-cut smear layer ${ }^{3,5)}$. 
Pashley reported that smear layer had low inherent bonding of $5 \mathrm{MPa}$ to the dentin substrate ${ }^{20)}$. Some studies have reported the physical methods for smear layer removal on flat dentin surface. Using extreme highpressure water spray at 4 atm for $3 \mathrm{~min}^{11)}$ was found to be the effective methods for removal of smear layer. However, these methods cannot be applied in a clinical situation. Moreover, Franca et al. has used $50 \mu \mathrm{m}$ aluminum oxide air abrasion on flat ground dentin and found that the method altered the surface morphology of dentin but did not improve the micro-tensile bond strength of two self-etching adhesives ${ }^{21)}$. Lee et al. found that application of the ultrasonic agitation of the primer of self- etching adhesive (One-Up Bond F) could improve the shear bond strength to dentin ${ }^{22)}$. On the other hands, Bagis et al. concluded that the ultrasonic agitation during self-etching adhesive application has no effect on adhesive performance ${ }^{23)}$. Therefore, the use of ultrasonic frequency for mechanical smear layer removal prior to the adhesive application was used in this study. Unfortunately, only acoustic streaming and cavitation effect from ultrasonication was not effective when applied on flat dentin in our pilot study. We therefore added on the brushing with ultrasonic frequency to enhance the cleaning effect. The results of our study clearly revealed that combination of brushing and ultrasonic cleansing at 10 and $30 \mathrm{~s}$ significantly reduce the thickness of smear layer. The first null hypothesis was thus rejected.

The aim of brushing with ultrasonic frequency is to transfer the vibration from ultrasonic tip to break the smear layer then flush out with water flow. Tensile modulus of soft toothbrush filament is approximately $500 \mathrm{kpsi}$ or $3.5 \mathrm{GPa}^{24)}$ while static elastic modulus of dentin is $10.1-19.3 \mathrm{GPa}^{25)}$. For this reason, it is unlikely that brushing will cause any abrasion on the dentin surface. Therefore, the dentin surface after ultrasonic application still has the grinding grooves from the diamond bur without additional damage.

For the smear layer characteristics after various treatments of this experiment, the dentin surface after brushing only show similar smear layer morphology as that of control group. The application of ultrasonic frequency to brushing demonstrate the good effective means for smear layer removal with dramatically decreasing smear layer thickness. This might be the additional effect from the movement of the tip of ultrasonic scaler other than the effect of mechanical removal with brushing. The high-power settings, coupled with long and slim probes are producing elliptical motion of the scaler tip ${ }^{26,27)}$. This phenomenon might break the smear layer adhesion and can be flushed them out with water. The cavitation effect around the ultrasonic tips might be adjunctive in smear layer removal also. Collapse of bubbles near a surface results in micro-jets that impact on a surface and aid surface cleaning $^{28)}$. Cavitational activity is enhanced at higher power settings and at longer operating times which increase smear layer cleaning effect ${ }^{15)}$.

For the effect of surface treatment on the $\mu$ SBS, the bond strength is improved with $30 \mathrm{~s}$ of ultrasonic brushing for both adhesives. The second null hypothesis was rejected. The improvement in bond strength may result from the effective smear layer removal prior to adhesive application after $30 \mathrm{~s}$ of ultrasonic brushing. The highest bond strength for both adhesives may result from thick hybrid layer, board base and high number of resin tags. Zhang et al. reported that if the resin wet the collagen fibrils that line the tubules might result in producing improved anchoring of resin tags in the tubules and improved stress transfer to resin bonded dentin ${ }^{29)}$. The smear layer and also smear plugs removal improved the wettability of adhesive to dentin surface resulting in improved bond strength. Eick et al. found that for the shear bond fracture specimen, the resin tags had broken off just below the surface of dentin (approximately 2-3 $\mu \mathrm{m})^{30)}$. From this finding, the base of resin tag might play the importance role in the bond strength value. The boarder base of resin tags found in specimen of $30 \mathrm{~s}$ of ultrasonic brushing group had larger area of adhesion which resulting in higher bond strength also. Many studies have found that bonding with mild selfetching adhesive showed higher bond strength to less thickness or less density of smear layer ${ }^{3,5,6,31)}$. However, some studies have reported that the performance of a self-etching system seems not to be dependent on the smear layer thickness or resin tags length ${ }^{4,32)}$.

CSE shows a significant higher bond strength than CTS with same surface treatment. This might be resulting from different type and acidity of each adhesive. CSE has separated acidic primer which has more acidity ( $\mathrm{pH}$ of CSE is 2.0 while CTS is 2.7) and wettability than all-in-one adhesive. Moreover, acidic primer can dissolve smear layer to obtain the bond to the underlying tooth surface ${ }^{3,33,34)}$. All-in-one adhesive is a mixture of hydrophilic and hydrophobic components in one bottle which affects the efficiency of each individual component. This may result in more prone of interfacial nano-leakage and lower long-term bonding effectiveness ${ }^{35,36)}$. Immediate bond strength of all-inone adhesive also lower than multi-step adhesive ${ }^{37,38)}$. However, Ito et al. has suggested that applying more coats of adhesive can be improved the strength and quality of dentin adhesion of all-in-one adhesives ${ }^{39}$.

For SEM observation of debonded dentin, most groups show adhesive failure predominately. Groups of CSE with ultrasonic brushing application show more mix failure or cohesive failure in dentin. This may relate to the high bond strength found in these groups more than the others.

SEM micrograph of resin-dentin interface supported the results of bond strength test. The ultrasonic brushing for $30 \mathrm{~s}$ group shows the thickest hybrid layer with board base of resin tags and the highest number of resin tags. Therefore, as mentioned previously, the thicker hybrid layer, more number of resin tags and boarder base of resin tags might result in higher bond strength for same adhesive. The more acidity of the adhesive, the more ability of adhesive to dissolve smear layer, demineralize dentin and create a thick hybrid layer ${ }^{32,33)}$. Moreover, when smear layer is loose or cleaned, buffering effect by 
the smear layer is reduced resulting in slightly greater etching effect of acidic monomer on peritubular dentin. This might be the reason of thicker hybrid layer, greater number of resin tags and conical-shape resin tags found in the group using CSE and ultrasonic brushing for 30 s. According to the report of Albaladejo et al., resin tags obtained with a two-step self-etching adhesive system and an etch-and-rinse adhesive system had conical shaped and showed lateral branches which is a sign of proper dentin infiltration ${ }^{40)}$.

This study clearly demonstrated that using this novel ultrasonic brushing on the dentin surface can improve the bond strengths of both two-step and onestep self etching adhesive. However, $30 \mathrm{~s}$ ultrasonic brushing is rather long for clinical application; further study is going on to shorter the ultrasonic brushing time using different type of bristle as well as frequency of ultrasonication.

\section{CONCLUSIONS}

Within the limitation of this study, it can be concluded that

1. The ultrasonic brushing application for $30 \mathrm{~s}$ is the effective method in mechanical removal of smear layer

2. The smear layer removal with ultrasonic brushing for $30 \mathrm{~s}$ can improve the bond strength of selfetching adhesive to coarse diamond bur prepared dentin.

\section{REFERENCES}

1) Pashley DH, Tay FR, Breschi L, Tjaderhane L, Carvalho RM, Carrilho M, Tezvergil-Mutluay A. State of the art etch-andrinse adhesives. Dent Mater 2011; 27: 1-16.

2) Van Meerbeek B, Yoshihara K, Yoshida Y, Mine A, De Munck J, Van Landuyt KL. State of the art of self-etch adhesives. Dent Mater 2011; 27: 17-28.

3) Oliveira SS, Pugach MK, Hilton JF, Watanabe LG, Marshall SJ, Marshall GW Jr. The influence of the dentin smear layer on adhesion: a self-etching primer vs. a total-etch system. Dent Mater 2003; 19: 758-767.

4) Shinoda Y, Nakajima M, Hosaka K, Otsuki M, Foxton RM, Tagami J. Effect of smear layer characteristics on dentin bonding durability of HEMA-free and HEMA-containing onestep self-etch adhesives. Dent Mater J 2011; 30: 501-510.

5) Sattabanasuk V, Vachiramon V, Qian F, Armstrong SR. Resin-dentin bond strength as related to different surface preparation methods. J Dent 2007; 35: 467-475.

6) Senawongse P, Srihanon A, Muangmingsuk A, Harnirattisai C. Effect of dentin smear layer on the performance of selfetching adhesive systems: A micro-tensile bond strength study. J Biomed Mater Res B Appl Biomater 2010; 94: 212221.

7) Osorio R, Erhardt MC, Pimenta LA, Osorio E, Toledano M. EDTA treatment improves resin-dentin bonds' resistance to degradation. J Dent Res 2005; 84: 736-740.

8) Imbery TA, Kennedy M, Janus C, Moon PC. Evaluating EDTA as a substitute for phosphoric acid-etching of enamel and dentin. Gen Dent 2012; 60: e55-61.

9) Kim DS, Park SH, Choi GW, Choi KK, Kim SY. Effect of EDTA treatment on the hybrid layer durability in total-etch dentin adhesives. Dent Mater J 2011; 30: 717-22.
10) Osorio R, Yamauti M, Osorio E, Ruiz-Requena ME, Pashley D, Tay F, Toledano M. Effect of dentin etching and chlorhexidine application on metalloproteinase-mediated collagen degradation. Eur J Oral Sci 2011; 119: 79-85.

11) Kusunoki M, Itoh K, Oikawa M, Hisamitsu H. Measurement of shear bond strength to intact dentin. Dent Mater J 2010; 29: 199-205.

12) Awad S. Ultrasonic cavitations and precision cleaning. Precision Cleaning 1996; 4: 12.

13) Azar L. Cavitation in ultrasonic cleaning and cell disruption. Controlled Environments 2009: 14-7.

14) Felver B, King DC, Lea SC, Price GJ, Damien Walmsley A. Cavitation occurrence around ultrasonic dental scalers. Ultrason Sonochem 2009; 16: 692-697.

15) Lea SC, Price GJ, Walmsley AD. A study to determine whether cavitation occurs around dental ultrasonic scaling instruments. Ultrason Sonochem 2005; 12: 233-236.

16) Mozo S, Llena C, Forner L. Review of ultrasonic irrigation in endodontics: increasing action of irrigating solutions. Med Oral Patol Oral Cir Bucal 2012; 17: e512-516.

17) Van der Sluis LW, Versluis M, Wu MK, Wesselink PR. Passive ultrasonic irrigation of the root canal: a review of the literature. Int Endod J 2007; 40: 415-426.

18) Marshall SJ, Bayne SC, Baier R, Tomsia AP, Marshall GW. A review of adhesion science. Dent Mater 2010; 26: e11-16.

19) Baier RE. Principles of adhesion. Oper Dent 1992; Suppl 5: $1-9$.

20) Pashley DH. The effects of acid etching on the pulpodentin complex. Oper Dent 1992; 17: 229-242.

21) Franca FM, dos Santos AJ, Lovadino JR. Influence of air abrasion and long-term storage on the bond strength of selfetching adhesives to dentin. Oper Dent 2007; 32: 217-224.

22) Lee J, Jang KT, Kim JW, Lee SH, Hahn SH, Kim CC. Effect of ultrasonic vibration on dentin bond strength and resin infiltration. Am J Dent 2003; 16: 404-408.

23) Bagis B, Turkaslan S, Vallittu PK, Lassila LV. Effect of high frequency ultrasonic agitation on the bond strength of selfetching adhesives. J Adhes Dent 2009; 11: 369-374.

24) Monohans Filaments. Technical bulletins.

25) Marshall GW Jr, Marshall SJ, Kinney JH, Balooch M. The dentin substrate: structure and properties related to bonding. J Dent 1997; 25: 441-458.

26) Lea SC, Felver B, Landini G, Walmsley AD. Threedimensional analyses of ultrasonic scaler oscillations. J Clin Periodontol 2009; 36: 44-50.

27) Lea SC, Walmsley AD. Mechano-physical and biophysical properties of power-driven scalers: driving the future of powered instrument design and evaluation. Periodontol 2000 2009; 51: 63-78.

28) Walmsley AD, Lea SC, Felver B, King DC, Price GJ. Mapping cavitation activity around dental ultrasonic tips. Clin Oral Investig 2013; 17: 1227-1234.

29) Zhang Z, Beitzel D, Mutluay M, Tay FR, Pashley DH, Arola D. On the durability of resin-dentin bonds: Identifying the weakest links. Dent Mater 2015; 31: 1109-1118.

30) Eick JD, Gwinnett AJ, Pashley DH, Robinson SJ. Current concepts on adhesion to dentin. Crit Rev Oral Biol Med 1997; 8: 306-335.

31) Tay FR, Pashley DH. Aggressiveness of contemporary selfetching systems. I: Depth of penetration beyond dentin smear layers. Dent Mater 2001; 17: 296-308.

32) Reis A, Grandi V, Carlotto L, Bortoli G, Patzlaff R, Rodrigues Accorinte Mde L, Dourado Loguercio A. Effect of smear layer thickness and acidity of self-etching solutions on early and long-term bond strength to dentin. J Dent 2005; 33: 549-559.

33) Kenshima S, Francci C, Reis A, Loguercio AD, Filho LE. Conditioning effect on dentin, resin tags and hybrid layer of different acidity self-etch adhesives applied to thick and thin smear layer. J Dent 2006; 34: 775-783. 
34) Tay FR, Carvalho R, Sano H, Pashley DH. Effect of smear layers on the bonding of a self-etching primer to dentin. J Adhes Dent 2000; 2: 99-116.

35) Suppa P, Breschi L, Ruggeri A, Mazzotti G, Prati C, Chersoni S, Di Lenarda R, Pashley DH, Tay FR. Nanoleakage within the hybrid layer: a correlative FEISEM/TEM investigation. J Biomed Mater Res B Appl Biomater 2005; 73: 7-14.

36) Tay FR, King NM, Chan KM, Pashley DH. How can nanoleakage occur in self-etching adhesive systems that demineralize and infiltrate simultaneously? J Adhes Dent 2002; 4: 255-269.

37) Sadek FT, Goracci C, Cardoso PE, Tay FR, Ferrari M. Microtensile bond strength of current dentin adhesives measured immediately and 24 hours after application. J
Adhes Dent 2005; 7: 297-302.

38) Van Landuyt KL, Mine A, De Munck J, Jaecques S, Peumans M, Lambrechts P, Van Meerbeek B. Are one-step adhesives easier to use and better performing? Multifactorial assessment of contemporary one-step self-etching adhesives. J Adhes Dent 2009; 11: 175-190.

39) Ito S, Tay FR, Hashimoto M, Yoshiyama M, Saito T, Brackett WW, Waller JL, Pashley DH. Effects of multiple coatings of two all-in-one adhesives on dentin bonding. J Adhes Dent 2005; 7: 133-141.

40) Albaladejo A, Osorio R, Toledano M, Ferrari M. Hybrid layers of etch-and-rinse versus self-etching adhesive systems. Med Oral Patol Oral Cir Bucal 2010; 15: e112-118. 